\title{
Are Conventional Complete Dentures Still Necessary? A Comparative Analysis of Two Groups of Completely Edentulous Patients
}

\author{
Uyiosa J Eregie ${ }^{1}$, Julie O Omo ${ }^{2}$, Matthew A Sede ${ }^{3}$, Temitope A Esan ${ }^{4}$
}

\begin{abstract}
Aim and objective: To compare the oral health-related quality of life (OHRQoL) of patients seeking complete denture treatment before rehabilitation with that of completely edentulous patients not seeking treatment using the Geriatric Oral Health Assessment Index (GOHAI) scale. Materials and methods: The study comprised two groups of completely edentulous patients with twenty patients in each group (group I and II). Group I patients comprised completely edentulous patients who sought treatment for their edentulous state. Their OHRQoL was assessed using the GOHAI scale before treatment and 3 months after treatment with complete dentures. Group II patients, on the other hand, comprised persons who were completely edentulous and have never sought treatment or used dentures. They filled the baseline GOHAI questionnaire only, following which oral health education was given to them. In addition to their OHRQoL assessment, their mental attitude toward treatment was also assessed for both groups of patients.

Results: The study comprised a total of forty completely edentulous patients with an age range of $60-89$ years and a mean age of $74.2 \pm 8.3$ years. A higher GOHAI-T mean score of $20.7 \pm 3.9$ was found among the non-denture wearers compared to $14.1 \pm 1.8$ observed in the complete denture wearers. However, a higher GOHAI-T mean score of $32.1 \pm 1.1$ was found among the complete-denture wearers 3 months after treatment with complete dentures compared to $20.7 \pm 3.9$ observed in the non-wearers at baseline.

Conclusion: The OHRQoL of completely edentulous non-denture wearers was observed to be higher than that of the completely edentulous denture wearers before rehabilitation. However, following rehabilitation with complete dentures, the OHRQoL of complete denture wearers was significantly higher than that of non-denture wearers.

Keywords: Complete denture, Edentulism, Quality of life.

International Journal of Prosthodontics and Restorative Dentistry (2021): 10.5005/jp-journals-10019-1303
\end{abstract}

\section{INTRODUCTION}

Complete edentulism, which refers to the total loss of all permanent teeth, ${ }^{1}$ is the outcome of a multi-factorial process involving biological factors (caries, periodontal disease, pulpal pathology, trauma, oral cancer), and nonbiological factors (access to care, patient's preferences, treatment options). ${ }^{2}$ Several studies have documented periodontal disease and dental caries as the commonest cause of tooth loss. ${ }^{3-7}$ Other less common causes of tooth loss include trauma, tooth impaction, malocclusion, and oral neoplasms. Complete edentulism is still considered a major public health problem because it impacts negatively on the oral healthrelated quality of life (OHRQoL) of millions of people throughout the globe. ${ }^{8}$

Complete dentures have been used conventionally as a means of rehabilitation for patients with complete edentulism and have been recognized to be the most common form of prosthetic rehabilitation for complete edentulism, ${ }^{9,10}$ especially in less developed countries with limited financial resources. Several studies conducted in the past have shown an improvement in the oral health-related quality of life of patients treated with complete dentures. ${ }^{11-14}$ However, most of these studies are hospital-based and are essentially conducted on patients who are motivated to wear dentures because they sought treatment for their edentulous state following which conclusions were thereafter generalized from such studies. Conversely, it has been observed that there are people who in most cases reside in rural indigent communities that have not seen the utmost need to seek treatment for their
${ }^{1}$ Department of Restorative Dentistry, University of Medical Sciences, Ondo City, Ondo State, Nigeria

${ }^{2,3}$ Department of Restorative Dentistry, University of Benin, Benin City, Edo, Nigeria

${ }^{4}$ Department of Restorative Dentistry, Obafemi Awolowo University, Ile Ife, Osun State, Nigeria

Corresponding Author: Uyiosa J Eregie, Department of Restorative Dentistry, University of Medical Sciences, Ondo City, Ondo State, Nigeria, Phone: +2348038630676, e-mail: uyiosaeregie@yahoo.com

How to cite this article: Eregie UJ, Omo JO, Sede MA, et al. Are Conventional Complete Dentures Still Necessary? A Comparative Analysis of Two Groups of Completely Edentulous Patients. Int J Prosthodont Restor Dent 2021;11(1):9-15.

Source of support: Nil

Conflict of interest: None

edentulous state. Most of them tend to associate loss of teeth with symptoms of old age, hence treatment may not be necessary according to them. Despite all the reported negative effects of complete edentulism on oral health as well as general health, these individuals have still managed to cope with their handicap and do not seem to be bothered about their condition. Although it has been established in some studies that OHRQoL is subjective and that the felt need of patients is different from the normative need, ${ }^{15-17}$ it is, therefore, necessary to assess the OHRQoL of these group of patients who have not sought treatment with complete 
dentures and are not motivated toward its use and compare the outcome with those patients who have decided to seek treatment before their rehabilitation. So far, no documented literature in our environment has assessed the OHRQoL of completely edentulous patients who have not sought treatment with complete dentures and are not motivated toward its use. This study will therefore bring to the fore reasons why some completely edentulous patients have never requested rehabilitation with conventional complete dentures despite its reported positive impact on the OHRQoL of patients.

\section{Materials and Methods}

This was a comparative interventional study comprising of two groups of completely edentulous patients with 20 patients in each group (group I and II). Group I patients comprised completely edentulous patients who sought treatment at the Prosthetics Clinic of University of Benin Teaching Hospital, Benin City, Nigeria during the one-year study period. Their OHRQoL was assessed using the Geriatric Oral Health Assessment Index (GOHAl) scale before treatment and 3 months after treatment with complete dentures.

Group II patients comprised persons who were completely edentulous and have never sought treatment or used dentures. They were recruited from rural communities located within Edo South senatorial district of Edo state. They filled the baseline GOHAl questionnaire only, following which oral health education was given to them. In addition to their OHRQoL assessment, their mental attitude toward treatment was also assessed for both groups of patients using the mental attitude assessment by $\mathrm{Dr}$ MM House which classified patients' attitude toward treatment as philosophical, exacting, hysterical, and indifferent. ${ }^{18}$ Ethical approval with protocol number ADM/E22/A/VOL.VII /1163 was obtained from the University of Benin Teaching Hospital Ethics and Research Committee before commencement of the study.

Data collected were analyzed using Statistical Package for Social Sciences (SPSS) version 21 for windows. Analysis was done and presented in frequencies and percentages. Association between discrete variables was tested using Chi-square. Measures of central tendency such as means and standard deviation were determined for the three domains of GOHAI as well as the total GOHAl score of both groups I and II. Differences between means was tested using Student's t-test, one-way ANOVA, and post hoc test (Bonferroni test). Statistically significant level was taken at $p<0.05$.

\section{Results}

The study comprised a total of forty completely edentulous patients with an age range of $60-89$ years and a mean age of $74.2 \pm 8.3$ years. There were more males than females with a male:female ratio of 1:0.8. The majority of the respondents were in the age group 60-69 years with $70 \%$ belonging to the unskilled occupational category. However, there were more unskilled participants among the nondenture wearers compared to the wearers. There was no skilled or semiskilled participant among the non-denture wearers. There was a statistically significant difference in the educational levels of the two groups ( $p=0.035)$. The majority of the study participants in group II (non-denture wearers) 14 (70\%) had received no form of formal education and none of them had been educated beyond the primary level while those in group I (denture wearers) had 11 (55\%) participants who were trained up to primary level and 1 (5\%) who had a tertiary level of education (Table 1). The non-denture wearers 7(35.0\%) were significantly involved in smoking cigarettes compared to complete denture wearers $(p=0.022)$. In addition, non-denture wearers were found to be significantly involved in tobacco use compared to complete denture wearers ( $p=0.001)$. Similarly, participants in group II were significantly involved in alcohol consumption than those in group I $(p=0.001)$ as shown in Table 2. There was a statistically significant difference between the mean duration of complete edentulism of the patients $(p=0.014)$, with non-denture wearers having a higher mean of $8.9 \pm 5.5$ years compared to complete denture wearers with a mean of $4.5 \pm 5.2$ years (Table 3). There was a significant difference in the distribution of the study participants in the two groups according to their mental attitude classification ( $p=0.0001)$. The majority $14(70.0 \%)$ of the complete denture wearers had a philosophical mental attitude accounting for $70 \%$ with 6 patients (30\%) having an exacting

Table 1: Sociodemographic characteristics of the patients

\begin{tabular}{|c|c|c|c|c|}
\hline Characteristics & $\begin{array}{l}\text { Complete } \\
\text { denture } \\
\text { wearers n (\%) }\end{array}$ & $\begin{array}{l}\text { Non-denture } \\
\text { wearers } \\
n(\%)\end{array}$ & $\begin{array}{l}\text { Total } \\
\text { sample } n(\%)\end{array}$ & $p$ value \\
\hline \multicolumn{5}{|l|}{ Age (years) } \\
\hline $60-69$ & $8(40.0)$ & $8(40.0)$ & $16(40.0)$ & $1.000^{*}$ \\
\hline $70-79$ & $6(30.0)$ & $6(30.0)$ & $12(30.0)$ & \\
\hline$\geq 80$ & $6(30.0)$ & $6(30.0)$ & $12(30.0)$ & \\
\hline \multicolumn{5}{|l|}{ Gender } \\
\hline Male & $11(55.0)$ & $11(55.0)$ & $22(55.0)$ & $1.000^{*}$ \\
\hline Female & $9(45.0)$ & $9(45.0)$ & $18(45.0)$ & \\
\hline \multicolumn{5}{|l|}{ Occupation } \\
\hline Skilled & $4(20.0)$ & $0(0.0)$ & $4(10.0)$ & $0.058^{\ddagger}$ \\
\hline Semiskilled & $2(10.0)$ & $0(0.0)$ & $2(5.0)$ & \\
\hline Unskilled & $12(60.0)$ & $16(80.0)$ & $28(70.0)$ & \\
\hline Dependent & $2(10.0)$ & $4(20.0)$ & $6(15.0)$ & \\
\hline \multicolumn{5}{|c|}{ Educational level } \\
\hline Nil & $6(30.0)$ & $14(70.0)$ & $20(50.0)$ & $0.035^{\ddagger}$ \\
\hline Primary & $11(55.0)$ & $6(30.0)$ & $17(42.5)$ & \\
\hline Secondary & $2(10.0)$ & $0(0.0)$ & $2(5.0)$ & \\
\hline Tertiary & $1(5.0)$ & $0(0.0)$ & $1(2.5)$ & \\
\hline
\end{tabular}

${ }^{*}$ Chi-square test, ${ }^{\dagger} \mathrm{Chi}$-square with Yates Correction, $T$-test, ${ }^{\ddagger}$ Fisher's exact test

Table 2: Smoking, tobacco, and alcohol habits of the patients

\begin{tabular}{|c|c|c|c|c|}
\hline $\begin{array}{l}\text { Habits of } \\
\text { patients }\end{array}$ & $\begin{array}{l}\text { Complete } \\
\text { denture } \\
\text { wearers } \\
\text { (group I) n (\%) }\end{array}$ & $\begin{array}{l}\text { Non-denture } \\
\text { wearers } \\
\text { (group II) } \\
n(\%)\end{array}$ & $\begin{array}{l}\text { Total sample } \\
n(\%)\end{array}$ & $p$ value \\
\hline \multicolumn{5}{|l|}{ Smoking } \\
\hline Yes & $1(5.0)$ & $7(35.0)$ & $8(20.0)$ & 0.022 \\
\hline No & $19(95.0)$ & $13(65.0)$ & $32(80.0)$ & \\
\hline \multicolumn{5}{|l|}{ Tobacco } \\
\hline Yes & $3(15.0)$ & $14(70.0)$ & $17(42.5)$ & 0.001 \\
\hline No & $17(85.0)$ & $6(30.0)$ & $23(57.5)$ & \\
\hline \multicolumn{5}{|l|}{ Alcohol } \\
\hline Yes & $2(10.0)$ & $14(70.0)$ & $16(40.0)$ & 0.001 \\
\hline No & $18(90.0)$ & $6(30.0)$ & $24(60.0)$ & \\
\hline Total & $20(100.0)$ & $20(100.0)$ & $40(100.0)$ & \\
\hline
\end{tabular}


attitude. None of the patients had a hysterical or indifferent mental attitude. On the contrary, the majority of the study participants in the non-denture wearer group (60\%) had an indifferent attitude. None of the non-denture wearers had a hysterical or exacting attitude (Table 4). In the denture-wearing group (group I), all 20 patients reported the inability to chew as a reason for seeking complete denture treatment in combination with other reasons such as inability to speak and esthetics (Fig. 1). In the non-denture wearing group, 10 patients (50\%) reported that using dentures was not a priority. Five patients accounting for $25 \%$ reported that they were not aware of dentures. Furthermore, the inability to afford the cost of treatment for complete dentures and the clinic being too far were reported by 15 and $10 \%$ of the participants (Fig. 2). Comparison of the OHRQoL between the complete denture wearers and non-wearers shows a statistically significant difference between the two groups in all domains as well as in the total GOHAl scores.

Table 3: Duration of complete edentulism among the complete denture wearers and non-wearers

\begin{tabular}{llll}
\hline Characteristics & $\begin{array}{l}\text { Complete denture } \\
\text { wearers Mean } \pm S D\end{array}$ & $\begin{array}{l}\text { Non-wearers } \\
\text { Mean } \pm S D\end{array}$ & p value \\
\hline $\begin{array}{l}\text { Duration of } \\
\text { edentulism (years) }\end{array}$ & $4.5 \pm 5.2$ & $8.9 \pm 5.5$ & 0.014 \\
\hline
\end{tabular}

Table 4: Mental attitude distribution among complete denture wearers and non-wearers

\begin{tabular}{|c|c|c|c|}
\hline \multirow[b]{2}{*}{ Mental attitude } & \multicolumn{2}{|c|}{ Groups } & \multirow[b]{2}{*}{$p$ value } \\
\hline & $\begin{array}{l}\text { Complete denture } \\
\text { wearers } n(\%)\end{array}$ & $\begin{array}{l}\text { Non-denture } \\
\text { wearers n (\%) }\end{array}$ & \\
\hline Philosophical & $14(70.0)$ & $8(40.0)$ & 0.0001 \\
\hline Exacting & $6(30.0)$ & $0(0.0)$ & \\
\hline Indifferent & $0(0.0)$ & $12(60.0)$ & \\
\hline Total & $20(100.0)$ & $20(100.0)$ & \\
\hline
\end{tabular}

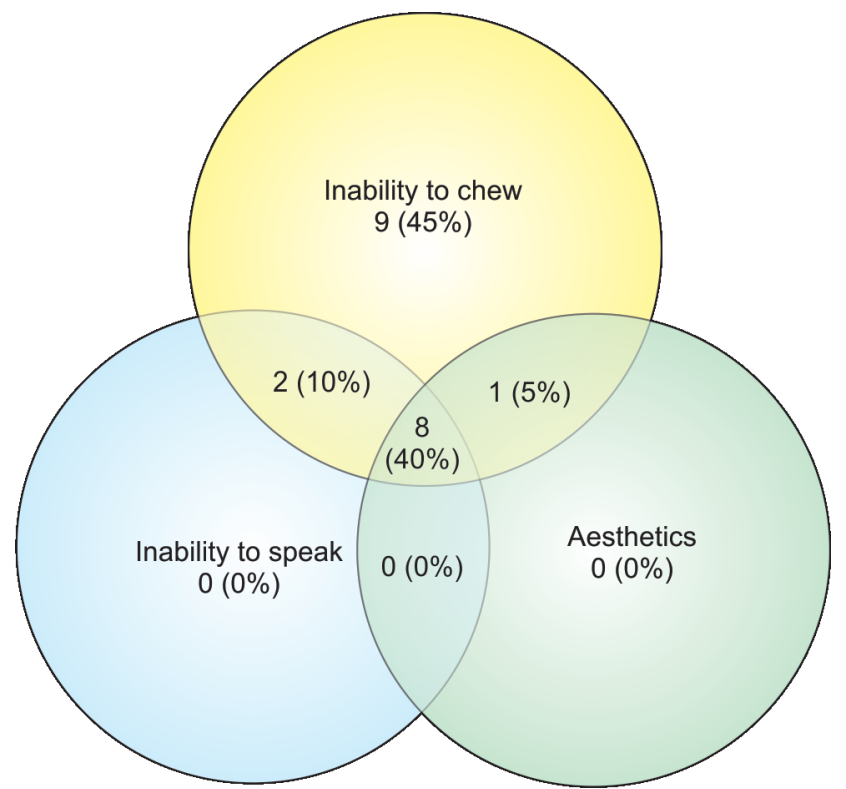

Fig. 1: Reasons for seeking complete denture treatment among patients (multiple responses)
A higher GOHAI-T mean score of $20.7 \pm 3.9$ was found among the non-denture wearers compared to $14.1 \pm 1.8$ observed in the complete denture wearers. The highest mean scores in both groups were noted in the psycho-social function domains with a mean score of $6.0 \pm 1.1$ for complete denture wearers and $10.1 \pm$ 3.2 for non-wearers. There was a significant difference in the mean scores between these groups ( $p=0.0001)$. The lowest mean scores were seen in the pain and discomfort domains for the complete denture wearers and non-wearers with a mean score of $3.7 \pm 1.0$ and $4.6 \pm 0.6$, respectively. The difference between these scores was found to be statistically significant $(p=0.0001)$ as shown in Table 5. Comparison of the OHRQoL between the complete denture wearers ( 3 months after treatment) and non-wearers (at baseline) shows a statistically significant difference between the two groups in all domains as well as the total GOHAl scores. A higher GOHAI-T mean score of $32.1 \pm 1.1$ was found among the complete-denture wearers compared to $20.7 \pm 3.9$ observed in the non-wearers. The highest mean scores in both groups were noted in the psychosocial function domains with a mean score of $14.7 \pm 0.7$ for complete denture wearers and $10.1 \pm 3.2$ for non-wearers. There was a significant difference in the mean scores between these groups $(p=0.0001)$. The lowest mean scores were seen in the pain and discomfort domains for the complete denture wearers and nonwearers with a mean score of $6.0 \pm 0.2$ and $4.6 \pm 0.6$, respectively. The difference between these scores was found to be statistically significant $(p=0.0001)$ as shown in Table 6.

Table 5: Comparison of the oral health-related quality of life of complete denture wearers (baseline) and non-denture wearers

\begin{tabular}{lccl}
\hline & $\begin{array}{l}\text { Complete } \\
\text { denture wearers } \\
\text { (baseline) }(n=20)\end{array}$ & $\begin{array}{l}\text { Non-denture } \\
\text { wearers }(n=20)\end{array}$ & \\
Characteristics & Mean $\pm S D$ & Mean $\pm S D$ & $p$ value \\
\hline Physical function & $4.5 \pm 0.6$ & $6.0 \pm 1.3$ & 0.0001 \\
Psychosocial function & $6.0 \pm 1.1$ & $10.1 \pm 3.2$ & 0.0001 \\
Pain and discomfort & $3.7 \pm 1.0$ & $4.6 \pm 0.6$ & 0.0001 \\
GOHAl-T scores & $14.1 \pm 1.8$ & $20.7 \pm 3.9$ & 0.0001 \\
\hline
\end{tabular}

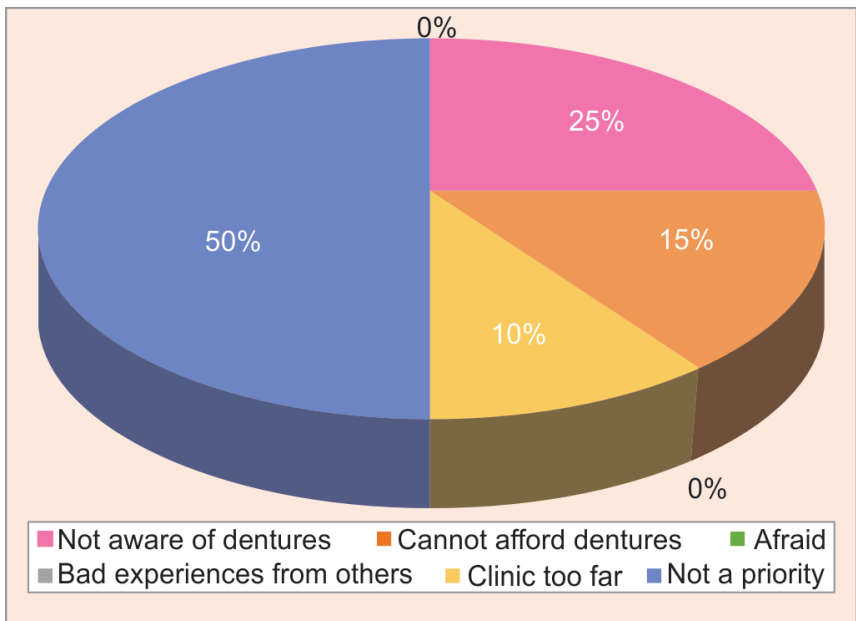

Fig. 2: Reasons for not seeking complete denture treatment among non-denture wearers 
Table 6: Comparison of the oral health-related quality of life of complete denture wearers ( 3 months after treatment) and non-denture wearers

\begin{tabular}{llcl}
\hline & $\begin{array}{l}\text { Complete denture } \\
\text { wearers (3 months } \\
\text { after treatment) } \\
\text { Mean } \pm S D\end{array}$ & $\begin{array}{l}\text { Non-denture } \\
\text { wearers } \\
\text { (baseline) } \\
\text { Mean } \pm S D\end{array}$ & p value \\
\hline Physacteristics & $11.5 \pm 0.6$ & $6.0 \pm 1.3$ & 0.0001 \\
Psychosocial function & $14.7 \pm 0.7$ & $10.1 \pm 3.2$ & 0.0001 \\
Pain and discomfort & $6.0 \pm 0.2$ & $4.6 \pm 0.6$ & 0.0001 \\
GOHAI-T scores & $32.1 \pm 1.1$ & $20.7 \pm 3.9$ & 0.0001 \\
\hline
\end{tabular}

\section{Discussion}

Complete edentulism, which refers to the total loss of all existing erupted natural teeth, has been documented to impact negatively on the OHRQoL of its sufferers. ${ }^{8}$ The use of conventional complete dentures is one of the commonest treatment options in the rehabilitation of complete edentulism and has been shown to improve the OHRQoL of patients. ${ }^{19,20}$ Despite some reported drawbacks with its use, it still remains a popular choice among the elderly population as they may also possess co-morbid conditions which may render them unfit for implant surgery, ${ }^{21,22}$ and also for its affordability. Most of the studies done in the past have been hospital-based and carried out on patients who presented for treatment and who could be termed "motivated". Little attention has been given to those patients who despite being completely edentulous have never presented for treatment notwithstanding the myriad of problems associated with being completely edentulous. There was therefore the need to assess the OHRQoL of these groups of completely edentulous non-denture wearers and compare the outcome with that of patients who have presented for complete denture treatment before rehabilitation. This study comprised two groups of completely edentulous elderly patients with 20 patients in each group. The mean age of $74.2 \pm 8.3$ years in this study was in accordance with a previous study ${ }^{23}$ but higher than those of other studies conducted on complete edentulous elderly patients. ${ }^{24,25} \mathrm{~A}$ male preponderance was observed in this study. This corroborates previous studies ${ }^{26,27}$ and was at variance with other studies. ${ }^{28,29}$ The male preponderance observed in this study could be attributed to the fact that the male gender is more prone to trauma beginning from an early age resulting in tooth $\operatorname{loss}^{30}$ and eventually, complete edentulism. The females, on the other hand, are more conscious about their oral health and have a more positive attitude toward their dental health, ${ }^{31,32}$ they therefore tend to retain their teeth till old age.

Most of the participants especially the non-denture wearers belonged to the unskilled occupational group comprising farmers, messengers, and cleaners. This was in agreement with previous studies. ${ }^{2,3}$ A finding that could be attributed to the fact that these groups of persons in the society belong to the low-income earners and may not be able to afford professional preventive oral care earlier in life. Individuals of a low socioeconomic status rarely seek dental care regularly due to a perceived high cost of dental treatment leading to an increased incidence of edentulous cases especially among the elderly. ${ }^{33,34}$ This finding was reported in a study conducted in a South-Western State of Nigeria in which it was reported that $52.8 \%$ of the elderly population surveyed had never visited a dentist; a situation which was attributed to a general lack of awareness about dental diseases and services, especially in rural areas. $^{35}$
A notable finding from this study is that majority of the patients had only been educated up to the primary level. The deficiency in formal education could have resulted in reduced awareness of preventive dental care, thereby acting as a contributory factor to complete edentulism. This finding had been documented by previous studies. ${ }^{2,3}$ It was also observed that the majority of the non-denture wearers especially the males were involved in habits such as tobacco use, smoking, and alcohol intake in comparison to the patients who sought treatment. This could be ascribed to the regular participation of the rural-based elderly in social gatherings such as traditional festivals, burial ceremonies, marriages, and community meetings where alcoholic drinks are usually served. This finding is in accordance with other studies conducted among the elderly dwelling in rural communities. ${ }^{36,37}$ It has been documented that indulging in habits such as alcohol, smoking, and tobacco use, especially when done excessively can contribute to oral health neglect. ${ }^{38}$ The involvement in such habits among the non-wearers may have contributed to their lack of motivation in seeking treatment to improve their oral health status. Common reasons for seeking treatment among denture wearers in this study in order of prevalence were inability to chew, inability to speak, and esthetics. This can be attributed to the fact that the elderly are more concerned with the functional properties of complete dentures rather than the psychosocial components such as esthetics and speech. This has been substantiated by a previous study. ${ }^{39}$ Leake et al. ${ }^{40}$ reported in their study that functionality was the main factor responsible for seeking treatment among patients. However, in another study, esthetics was given much more important than function as a reason for seeking treatment. ${ }^{41}$ The reason for their finding could be attributed to the fact that their sample population comprises younger patients who are usually more particular about their appearance compared to the elderly. Despite the documented benefits of the use of complete dentures, ${ }^{11,13,29}$ the non-denture wearers also gave reasons for not seeking treatment. The commonest reason given was "use of dentures not being a priority". This was reported by $50 \%$ of the participants. This is understandable as the elderly are usually afflicted with one or more systemic diseases that have an obvious effect on mobility and well-being. In addition to their immediate need of food and care for the family. Other reasons given for not seeking treatment were unawareness of complete dentures, financial constraints, and the clinic being too far from their places of residence. This may be because preference is usually given to general health rather than oral health in our environment, especially among patients residing in rural communities. ${ }^{33}$ They are therefore not willing to spend their already lean resources on improving their oral health as they do not see it as an emergency, hence the nonchalant attitude toward treatment. Furthermore, the mean duration of edentulism (years) was observed to be higher among the non-denture wearer group than the complete denture wearers. The longer duration of the edentulous state among the non-denture wearers may be attributed to a lack of motivation to seek treatment probably as a result of an adaptation to their edentulous state. The wearers who sought treatment apparently were more motivated toward treatment and probably could not tolerate their edentulous state any further. An evaluation of the mental attitude of the patients studied revealed that the majority of the patients who sought complete denture treatment were philosophical in attitude with very few exhibiting an exacting attitude. No patient seeking treatment showed a hysterical or an indifferent attitude to treatment. This could be a 
pointer to the fact that most patients who present for complete denture treatment are motivated toward its use and are willing to cooperate with the dentist in ensuring a favorable outcome. Other studies have also validated this finding. ${ }^{42,43}$ The non-denture wearers, on the other hand, were more indifferent in their attitude than philosophical even after oral health education had been given to them. This may be due to their ingrained cultural beliefs as well as an adaptive response to their completely edentulous state. In a study conducted among several rural communities in Nigeria, it was reported that the treatment-seeking behavior of the elderly, their lifestyle, habits, and values tend to be both culturally related and restrictive. ${ }^{44}$ The illiterate elderly populace who reside in rural communities devoid of modern healthcare facilities are believed to engage in a kind of cost-benefit analysis wherein the benefits of their actions are weighed against perceptions that it may be expensive, unpleasant, inconvenient, time-consuming, and may even be harmful based on their cultural beliefs and exercises. ${ }^{44}$ If the oral health action is perceived as inaccessible, inconvenient, or unpleasant, they are less likely to partake in it. ${ }^{44} \mathrm{~A}$ comparative assessment of the OHRQoL of both groups of patients at baseline revealed that the completely edentulous non-denture wearers had a higher mean GOHAI score when compared to patients who sought complete denture treatment before rehabilitation. This finding could be attributed to an adaptation to their edentulous state and a reported higher use of tobacco and alcohol by the non-denture wearers which might give them a false sense of satisfaction. Hence, they lack the motivation to seek treatment. Before rehabilitation, the OHRQoL of non-denture wearers was higher than that of patients seeking treatment. However, following rehabilitation with complete dentures, there was a significant increase in the OHRQoL of the complete denture wearers at 3 months post-treatment in comparison to that of the non-denture wearers. Although it may initially seem that the OHRQoL of unmotivated non-denture wearers appear higher in comparison to patients who sought treatment probably due to their adaptive state of their long-term edentulousness, in the long run, it has been proven once more that conventional complete dentures still impact positively on the OHRQoL of completely edentulous patients and therefore still very relevant as a treatment option for complete edentulism.

\section{CONCLUSION}

The OHRQoL of completely edentulous non-denture wearers was observed to be higher than that of the completely edentulous denture wearers before rehabilitation. However, following rehabilitation with complete dentures, the OHRQoL of complete denture wearers was significantly higher than that of edentulous patients who did not seek treatment. Hence, conventional complete dentures still remain a viable treatment option in the management of complete edentulism as it significantly improves the OHRQoL of patients.

\section{References}

1. The glossary of prosthodontic terms. J Prosthet Dent 2005;94(1):1092. DOI: 10.1016/j.prosdent.2005.03.013.

2. Al Hamdan E, Fahmy MM. Socioeconomic factors and complete edentulism for female patients at King Saud University, Riyadh, Saudi Arabia. Tanta Dent J 2014;11(3):169-173. DOI: 10.1016/j.tdj.2014.09.002.

3. Esan TA, Olusile AO, Akeredolu PA, et al. Socio-demographic factors and edentulism: the Nigerian experience. BMC Oral Health 2004;4(1):3. DOI: 10.1186/1472-6831-4-3.
4. Odusanya SA. Tooth loss among Nigerians: causes and pattern of mortality. Int J Oral Maxillofac Surg 1987;16(2):184-189. DOI: 10.1016/ s0901-5027(87)80128-5.

5. Saheeb BD, Sede MA. Reasons and pattern of tooth mortality in a Nigerian Urban teaching hospital. Ann Afr Med 2013;12(2):110-114. DOI: 10.4103/1596-3519.112402.

6. Esan TA, Olusile AO, Ojo MA, et al. Tooth loss among Nigerians treated in teaching hospitals: a national pilot study. J Contemp Dent Practice 2010;11(5):017-024. DOI: 10.5005/jcdp-11-5-17.

7. Baelum $V$, Fejerskov $O$. Tooth loss as related to dental caries and periodontal breakdown in adult Tanzanians. Community Dent Oral Epidemiol 2006;14(6):353-357. DOI: 10.1111/j.1600-0528.1986. tb01090.x.

8. Samara SA, Haidar ZS. Re-visiting edentulism: complete removable dentures vs implant overdentures. J Oral Health Comm Dent 2011;5(3):107-109.

9. Roessler D. Complete denture success for patients and dentists. Int Dent J 2003;53(5 Suppl):340-345. DOI: 10.1111/j.1875-595x.2003. tb00908.x.

10. Jones JA, Orner MB, Spiro IIIA, et al. Tooth loss and dentures: patients' perspectives. Int J Dent 2003;53(S5):327-334. DOI: 10.1111/j.1875595x.2003.tb00906.x.

11. Shigli K, Hebbal M. Assessment of changes in oral health-related quality of life among patients with complete denture before and 1-month post-insertion using geriatric oral health assessment index. Gerodontol 2010;27(3):167-173.DOI: 10.1111/j.1741-2358.2009.00323.x.

12. Nitschke I, Müller $F$. The impact of oral health on the quality of life in the elderly. Oral Health Prev Dent 2004;2(Suppl 1):271-275.

13. Allen PF, McMillan AS. A longitudinal study of quality-of-life outcomes in older adults requesting implant prostheses and complete removable dentures. Clin Oral Implants Res 2003;14(2):173-179. DOI: 10.1034/j.1600-0501.2003.140206.x.

14. de Souza e Silva ME, de Magalhães CS, Ferreira e Ferreira E. Complete removable prostheses: from expectation to (dis) satisfaction. Gerodontol 2009;26(2):143-149. DOI: 10.1111/j.17412358.2008.00243.x.

15. Tsakos G. Combining normative and psychosocial perceptions for assessing orthodontic treatment needs. J Dent Educ 2008;72(8):876885. DOI: 10.1002/j.0022-0337.2008.72.8.tb04563.x.

16. Ghijseling I, Brosens V, Willems G, et al. Normative and self-perceived orthodontic treatment need in 11- to 16-year-old children. Eur J Orthod 2014;36(2):179-185. Available online: www.ncbi.nlm.nih.gov/ pubmed/23761429. (Accessed 7th April 2021).

17. Oshagh $M$, Salehi P, Pakshir H, et al. Associations between normative and self-perceived orthodontic treatment needs in young-adult dental patients. Korean J Orthod 2011;41(6):440-446. DOI: 10.4041/ kjod.2011.41.6.440.

18. House MM. Studies in prosthesis. J Am Dent Assoc 1931;18:827-852.

19. Crocombe LA, Mejia GC, Koster CR, et al. Comparison of adult oral health in Australia, the USA, Germany and the UK. Aust Dent J 2009;54(2):147-153. DOI: 10.1111/j.1834-7819.2009.01108.x.

20. Veyrune JL, Tubert-Jeannin S, Dutheil C, et al. Impact of new prostheses on the oral health related quality of life of edentulous patients. Gerodontol 2005;22(1):3-9. DOI: 10.1111/j.1741-2358.2004.00048.x.

21. Fitzpatrick AL, Powe NR, Cooper LS, et al. Barriers to health care access among the elderly and who perceives them. Am J Pub Health 2004;94(10):1788-1794. DOI: 10.2105/ajph.94.10.1788.

22. Dolan TA, Atchison K, Huynh TN. Access to dental care among older adults in the United States. J Dent Educ 2005;69(9):961-974. DOI: 10.1002/j.0022-0337.2005.69.9.tb03993.x.

23. Zmyslowska E, Ledzion S, Jedrzejewski K. Factor's affecting mandibular residual ridge resorption in edentulous patients: a preliminary report. Folia Morphol (Warsz) 2007;66(4):346-352.

24. Akinboboye BO, Akeredolu PA, Sofola O, et al. Utilization of teeth replacement service among the elderly attending teaching hospitals in Lagos, Nigeria. Ann Med Health Sci Res 2014;4(1):57-60. DOI: 10.4103/2141-9248.126613. 
25. Rajani AD, Babita JY, Saurabh SM, et al. Tooth loss - how emotional it is for the elderly in India? OHDM 2014;13(2):305-310.

26. Taiwo JO, Omokhodion F. Pattern of tooth loss in an elderly population from Ibadan. Nigeria Gerondontol 2006;23(2):117-122. DOI: 10.1111/j.1741-2358.2006.00107.x.

27. Narain U, Garg R, Sameer, et al. A prospective study of the quality of removable prostheses and patients' satisfaction in post-prosthetic phase. Internet J Dent Sci 2009;9(1):1937-8238.

28. Rajani AD, Girish SN, Shailendra BS, et al. Assessment of oral health related quality of life among completely edentulous patients in Western India by using GOHAl. J Clin Diagn Res 2013;7(9):2063-2067.

29. Adam RZ, Do Complete Dentures Improve the Quality of Life of Patients? (Thesis) University of Western Cape. 2006.

30. Akeredolu PA, Omitola OG, Savage KOAge. Gender and pattern of tooth replacement at Lagos University teaching hospital. Nig Qt J Hosp Med 2004;14(1):45-48.

31. Ostberg AL, Halling A, Lindblad U. Gender differences in knowledge, attitude, behavior and perceived oral health among adolescents. Acta Odontol Scand 1999:57(4):231-236. DOI: 10.1080/000163599428832.

32. Fukai K, Takaesu Y, Maki Y. Gender differences in oral health. Behavior and general health habits in an adult population. Bulletin Tokyo Dent Coll 1999;40(4):187-193. DOI: 10.2209/ tdcpublication.40.187.

33. Owotade FJ, Ogunbodede EO, Lawal AA. Oral diseases in the elderly, a study in lle-Ife, Nigeria. J Soc Sci 2005;10(2):105-110. DOI: 10.1080/09718923.2005.11892465.

34. Thompson GW, Kreisel PS. The impact of the demographics of aging and the edentulous condition on dental care services. J Prosthet Dent 1998;79(1):56-59. DOI: 10.1016/s0022-3913(98)70194-5.

35. Subramanian SV, Nandy S, Kelly M, et al. Patterns and distribution of tobacco consumption in India: cross sectional multilevel evidence from the 1998-9 national family health survey. Brit Med $J$ 2004;328(7443):801-806. DOI: 10.1136/bmj.328.7443.801.

36. Chukwuonye II, Chuku A, Onyeonoro UU, et al. A rural and urban cross-sectional study on alcohol consumption among adult Nigerians in Abia state. Int J Med Biomed Res 2013;2(3):179-185. DOI: 10.14194/ ijmbr.234.

37. Neufeld KJ, Peters DH, Rani M, et al. Regular use of alcohol and tobacco in India and its association with age, gender, and poverty. Drug Alcohol Depend 2005;77(3):283-291. DOI: 10.1016/j. drugalcdep.2004.08.022.

38. Friedlander AH, Norman DC. Geriatric alcoholism pathophysiology and dental implications. JADA 2006;137(3):330-338. DOI: 10.14219/ jada.archive.2006.0182.

39. Muhammad RM, Fazal G, Muhammad S. Functional assessment of removable complete dentures. Pak Oral Dent J 2013;33(3):563-565.

40. Leake JL, Hawkins R, Locker D. Social and functional: impact of reduced posterior dental units in older adults. J Oral Rehabil 1994;21(1):1-10. DOI: 10.1111/j.1365-2842.1994.tb01119.x.

41. Mukatash GN, Al-Rousan M, Al-Sakarna B. Needs and demands of prosthetic treatment among two groups of individuals. Indian J Dental Res 2010;21(4):564-567. DOI: 10.4103/0970-9290.74221.

42. Shweta C, Ajit K, Himanshu A. Correlation of patient's mental attitude with age, sex, and educational level: a survey. Eur J Dent 2016;10(1):23-28. DOI: 10.4103/1305-7456.175688.

43. Murthy JV, Singh S, Shakila R, et al. Comparison of grapho-analysis with house method in prediction of complete denture patient's mental attitude: a prospective comparative study. J Indian Prosthodont Soc 2013;13(1):24-29. DOI: 10.1007/s13191-012-0155-4.

44. Fajemilehin BR, Ogunbodede E. Oral health behaviour among the elderly in Osun State. Nig J Soc Sci 2002;6(4):257-261. DOI: $10.1080 / 09718923.2002 .11892354$. 
Questions and responses for the 11-item modified GOHAl questionnaire

\begin{tabular}{l}
\hline In the past (1 or 3) Months... \\
\hline 1. How often did you limit the kinds of food eaten? because of problems with \\
your teeth, gums, or dentures? \\
2. How often did you have trouble biting or chewing any kind of food, such as \\
firm meat or apples? \\
3. How often were you able to swallow comfortably? \\
4. How often have your teeth, gums, or dentures prevented you from \\
speaking the way you wanted? \\
5. How often were you able to eat anything without feeling discomfort? \\
6. How often did you limit contact with people because of the condition of \\
your teeth, mouth, or dentures? \\
7. How often were you pleased or happy with the looks of your teeth, gums, \\
or dentures? \\
8. How often did you use medication to relieve pain or discomfort from \\
around your mouth? \\
9. How often were you worried or concerned about problems with your teeth, \\
gums, or dentures? \\
10. How often did you feel nervous or self-conscious because of problems with \\
your teeth, gums, or dentures? \\
11. How often did you feel uncomfortable eating in front of others because of \\
problems with your teeth, mouth, or dentures?
\end{tabular}

Always $=1$, Sometimes $=2$, Never $=3$ 